\title{
Molecular alterations in endometrial and ovarian clear cell carcinomas: clinical impacts of telomerase reverse transcriptase promoter mutation
}

Hsien-Neng Huang 1,2,7, Ying-Cheng Chiang,3,7, Wen-Fang Cheng ${ }^{3,4,5}$, Chi-An Chen ${ }^{3}$, Ming-Chieh $\operatorname{Lin}^{6}$ and Kuan-Ting Kuo ${ }^{1,6}$

${ }^{1}$ Department of Pathology, College of Medicine, Graduate Institute of Pathology, National Taiwan University, Taipei, Taiwan; ${ }^{2}$ Department of Pathology, National Taiwan University Hospital Hsin-Chu Branch, Hsinchu, Taiwan; ${ }^{3}$ Department of Obstetrics and Gynecology, College of Medicine, National Taiwan University, Taipei, Taiwan; ${ }^{4}$ Graduate Institute of Clinical Medicine, College of Medicine, National Taiwan University, Taipei, Taiwan; ${ }^{5}$ Graduate Institute of Oncology, College of Medicine, National Taiwan University, Taipei, Taiwan and ${ }^{6}$ Department of Pathology, College of Medicine, National Taiwan University Hospital, National Taiwan University, Taipei, Taiwan

Recently, mutations of telomerase reverse transcriptase (TERT) promoter were found in several types of cancer. A few reports demonstrate TERT promoter mutations in ovarian clear cell carcinomas but endometrial clear cell carcinoma has not been studied. The aims of this study were to compare differences of molecular alterations and clinical factors, and identify their prognostic impact in endometrial and ovarian clear cell carcinomas. We evaluated mutations of the TERT promoter and PIK3CA, expression of ARID1A, and other clinicopathological factors in $\mathbf{5 6}$ ovarian and $\mathbf{1 4}$ endometrial clear cell carcinomas. We found that TERT promoter mutations were present in $21 \%(3 / 14)$ of endometrial clear cell carcinomas and $16 \%(9 / 56)$ of ovarian clear cell carcinomas. Compared with ovarian clear cell carcinomas, endometrial clear cell carcinomas showed older mean patient age $(P<0.001)$, preserved ARID1A immunoreactivity $(P=0.017)$ and infrequent $P I K 3 C A$ mutation $(P=0.025)$. In ovarian clear cell carcinomas, TERT promoter mutations were correlated with patient age $>45(P=0.045)$ and preserved ARID1A expression $(P=0.003)$. In cases of endometrial clear cell carcinoma, TERT promoter mutations were not statistically associated with any other clinicopathological factors. In ovarian clear cell carcinoma patients with early FIGO stage (stages I and II), TERT promoter mutation was an independent prognostic factor and correlated with a shorter disease-free survival and overall survival $(P=0.015$ and 0.009 , respectively). In recurrent ovarian clear cell carcinoma patients with early FIGO stage, TERT promoter mutations were associated with early relapse within 6 months $(P=0.018)$. We concluded that TERT promoter mutations were present in endometrial and ovarian clear cell carcinomas. Distinct molecular alteration patterns in endometrial and ovarian clear cell carcinomas implied different processes of tumorigenesis in these morphologically similar tumors. In ovarian clear cell carcinoma of early FIGO stage, patients with TERT promoter mutation require close follow-up during the initial 6 months following chemotherapy.

Modern Pathology (2015) 28, 303-311; doi:10.1038/modpathol.2014.93; published online 1 August 2014

Ovarian clear cell carcinoma represents $5-25 \%$ of all epithelial ovarian carcinomas with geographic variation. ${ }^{1}$ Compared with high-grade serous

Correspondence: Dr K-T Kuo, MD, Department of Pathology, College of Medicine, National Taiwan University Hospital, National Taiwan University, Taiwan, 3rd floor, No. 7, Chung Shan South Road, Taipei 10001, Taiwan.

E-mail: pathologykimo@gmail.com

${ }^{7}$ These authors contributed equally to this work.

Received 24 February 2014; accepted 10 May 2014; published online 1 August 2014 adenocarcinomas, ovarian clear cell carcinomas are characterized by a higher incidence among Asians, younger patient age and early tumor staging at presentation, association with endometriosis, higher frequencies of AT-rich interactive domain 1 A (ARID1A) mutation and phosphatidylinositol-4,5-bisphosphate 3-kinase, catalytic subunit alpha (PIK3CA) mutation, and higher resistance to first-line platinum and taxane-based chemotherapy. ${ }^{2-4}$ 
Primary endometrial clear cell carcinoma (which has similar histologic characteristics to ovarian clear cell carcinoma) is a rare histologic type that accounts for less than $3 \%$ of all endometrial carcinomas. ${ }^{5,6}$ Interobserver reproducibility of endometrial clear cell carcinoma was poor, ${ }^{7,8}$ and a panel of hepatocyte nuclear factor- $1 \beta$ (HNF-1 $\beta$ ) and estrogen receptor (ER) immunohistochemistry was suggested for differentiation of endometrial clear cell carcinoma from endometrioid and serous carcinoma. ${ }^{9}$ Owing to the rarity of endometrial clear cell carcinoma, information on the molecular characterization of this tumor is limited. Previous studies demonstrated that loss of ARID1A expression occurred in $22.7 \%^{10}$ to $40 \%{ }^{11}$ of endometrial clear cell carcinomas but mutations of the TP53 or PTEN gene were uncommon. ${ }^{12}$

Telomeres are located at the ends of eukaryotic chromosomes and are crucial for chromosomal integrity and avoidance of cell death or senescence. Telomerase is a ribonucleoprotein and can add TTAGGG hexamers to the ends of chromosomes. ${ }^{13}$ Telomerase activity is generally higher in cancer cells than normal cells and is required to maintain tumor growth. ${ }^{13}$ Telomerase reverse transcriptase (TERT) is a catalytic subunit of telomerase, ${ }^{14}$ and increased activity of TERT is present in most cancers, including ovarian cancer. ${ }^{14,15}$ Mutations of TERT promoter contribute to a mechanism that allows for increased telomerase activity and is found in melanomas, ${ }^{16,17}$ thyroid carcinomas, ${ }^{18,19}$ myxoid liposarcomas, hepatocellular carcinomas, urothelial carcinomas, squamous cell carcinomas of the tongue, medulloblastomas, and gliomas. ${ }^{20}$ Most TERT promoter mutations in malignancies are located at two hotspots, $-124 \mathrm{C}>\mathrm{T}$ and $-146 \mathrm{C}>\mathrm{T} .{ }^{20}$ The mutations of the TERT promoter in these two hotspots lead to the creation of E-twenty-six/ternary complex factor-binding motifs and a subsequent increase in transcription. ${ }^{16,17}$

Only two previous reports have studied TERT promoter mutations in cancers of the gynecologic tract. $^{20,21}$ Killela et $a l^{20}$ described the presence of TERT promoter mutations in endometrial, ovarian, and cervical cancer. Wu et $a l^{21}$ reported that ovarian clear cell carcinoma was the predominant histologic type of gynecological malignancy that harbored mutations of the TERT promoter. However, TERT promoter mutations of endometrial clear cell carcinoma have not been studied. Molecular genetic differences between endometrial and ovarian clear cell carcinoma are also still unclear. Therefore, we analyzed mutations of the TERT promoter and PIK3CA, expression of ARID1A, and clinical information in endometrial and ovarian clear cell carcinomas. Then we evaluated the molecular and clinical differences in endometrial and ovarian clear cell carcinomas, relationships between TERT promoter mutations, and other clinicopathological factors, and prognostic impacts of these clinicopathological factors in ovarian clear cell carcinomas.

\section{Materials and methods}

\section{Patients and Tissue Materials}

Seventy formalin-fixed, paraffin-embedded tissue specimens (56 ovarian and 14 endometrial clear cell carcinomas) were obtained from the archives of 1995-2011, at the Department of Pathology of National Taiwan University Hospital. Some cases of ovarian clear cell carcinoma were also reported in our previous study. ${ }^{22}$ All patients underwent operations including total hysterectomy with bilateral salpingo-oophorectomy, at least, and no concurrent endometrial and ovarian clear cell carcinomas were found. All patients with ovarian clear cell carcinoma underwent debulking surgery. The specimens were diagnosed as pure ovarian or endometrial clear cell carcinoma according to the World Health Organization classification. ${ }^{23}$ Except for pure and typical morphology, cases of endometrial clear cell carcinoma in this study were diffusely positive for the HNF-1 $\beta$ immunostain but negative or focally positive $(<10 \%)$ for ER immunostain (Figure 1).

\section{Immunohistochemistry}

Immunohistochemical staining of ARID1A was performed with protocols as previously described. ${ }^{22}$ The ARID1A immunoreactivities were divided into either undetectable or positive (weakly or strongly) for nuclear staining, and stromal cells were used as an internal positive control. ${ }^{24}$

\section{DNA Extraction and Mutation Analysis}

DNA extraction, polymerase chain reaction (PCR) amplification for sequencing of the TERT promoter and the PIK3CA gene were performed in all cases by protocols as previously described.,16 Tumor components from formalin-fixed and paraffin-embedded tissue blocks were manually dissected from $10-\mu \mathrm{m}$ sections. Genomic DNA of tumor tissue was extracted using the QIAmp DNA FFPE tissue kit (Qiagen, CA). The primer sets used for PIK3CA were listed as follows: 5 '-TCAGCAGTTACTATTCTGTGACTGG-3' (forward primer) and 5'-GTAAAACGACGGCCAG TTGCTGAGATCAGCCAAATTCA-3' (reverse primer) for exon 9, as well as $5^{\prime}$-GTAAAACGACGGCCAG TGACATTTGAGCAAAGACCTGAAG- $3^{\prime}$ (forward primer) and $5^{\prime}$-TGGATTGTGCAATTCCTATGC- ${ }^{\prime}$ (reverse primer) for exon 20. ${ }^{3}$ Two primer sets were used for TERT promoter. ${ }^{16}$ Primer set no. 1 was $5^{\prime}$ ACGAACGTGGCCAGCGGCAG-3' (forward primer) and $5^{\prime}$-CTGGCGTCCCTGCACCCTGG- $3^{\prime}$ (reverse primer) and the product was $474 \mathrm{bps}$ in length. Primer set no. 2 was employed in cases where amplification of the fragment failed. The primer set no. 2 was $5^{\prime}$ CAGCGCTGCCTGAAACTC- $3^{\prime}$ (forward primer) and 5'-GTCCTGCCCCTTCACCTT-3' (reverse primer). 

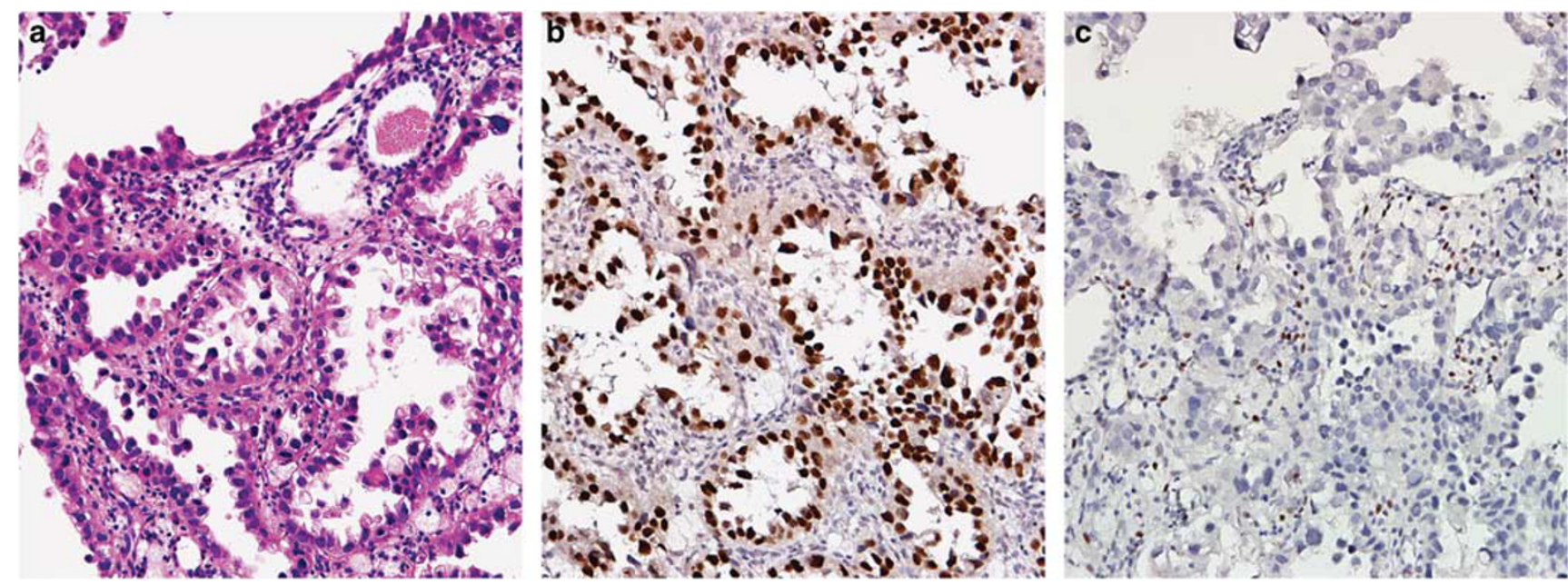

Figure 1 Representative hematoxylin and eosin-stained sections (a) and immunohistochemistry for HNF-1 $\beta$ (b) and ER (c) of endometrial clear cell carcinoma used in the study.

a

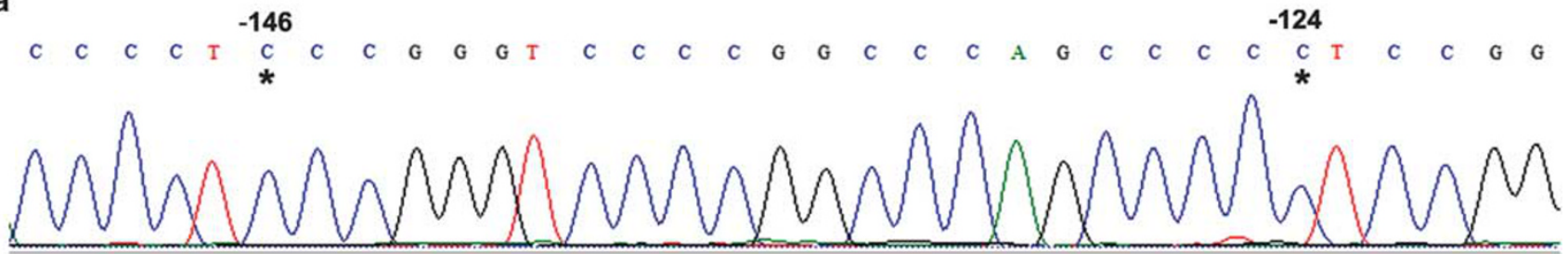

b

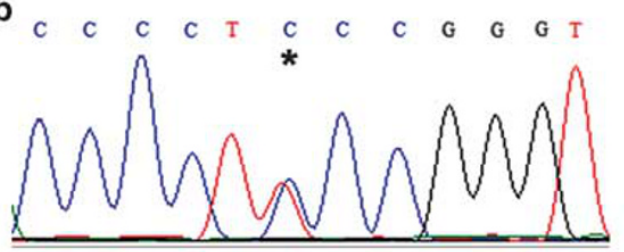

d

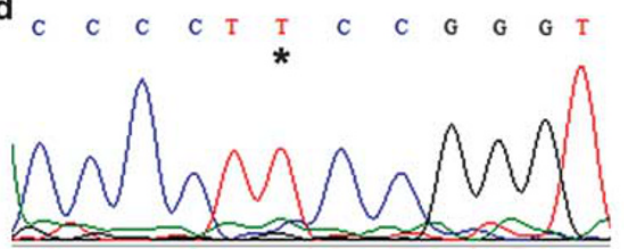

Endometrial clear cell carcinoma
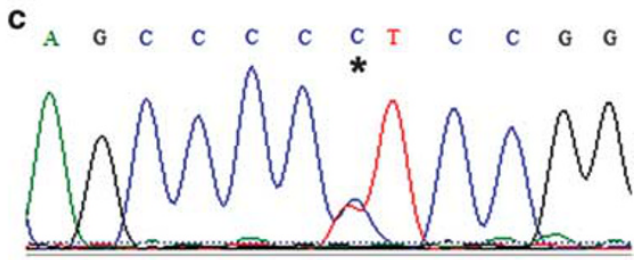

Ovarian clear cell carcinoma e

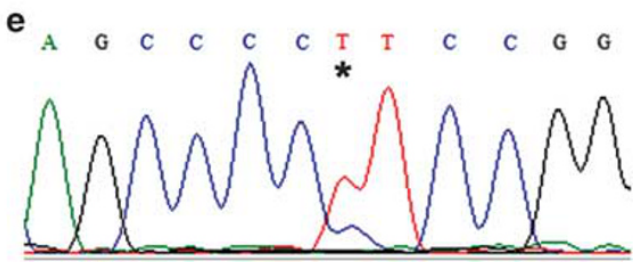

Figure 2 Representative chromatograms of wild-type TERT promoter (a) and mutational status of endometrial (b, c) and ovarian (d, e) clear cell carcinomas at two different hotspots (highlighted by asterisks), $-124 \mathrm{C}>\mathrm{T}$ and $-146 \mathrm{C}>\mathrm{T}$.

Sanger DNA sequencing was performed using ABI 3730 DNA Analyzer (Life Technologies, NY).

\section{Statistical Analysis}

The statistical analyses were conducted using PASW Statistics (IBM Corporation, Armonk, NY, USA). Comparison of molecular alterations in endometrial and ovarian clear cell carcinomas, as well as associations between TERT promoter mutation and other clinicopathological factors, were evaluated using the $\chi^{2}$ test or Fisher's exact test. Mann-Whitney $U$-test was used to assess the differences in age between patients with endometrial and ovarian clear cell carcinomas. The influences of clinicopathological parameters on disease-free survival and overall survival were analyzed by Cox proportional hazard model. P-values from Wald's statistic were recorded. The Kaplan-Meier survival analysis with log-rank significance test was used to estimate the probabilities of survival. The cutoff of significance level was 0.05 . 
Table 1 Comparison of clinicopathological factors between endometrial and ovarian clear cell carcinomas

\begin{tabular}{lccr}
\hline & $\begin{array}{c}\text { Endometrial } \\
(\mathrm{n}=14)\end{array}$ & $\begin{array}{c}\text { Ovarian } \\
(\mathrm{n}=56)\end{array}$ & P-value \\
\hline $\begin{array}{l}\text { Mean age } \\
\begin{array}{l}\text { Loss of ARID1A } \\
\text { expression }\end{array}\end{array}$ & 31 Years & 48 Years & $<0.001$ \\
$\begin{array}{l}\text { TERT promoter } \\
\text { mutation }\end{array}$ & $3(21 \%)$ & $32(57 \%)$ & 0.017 \\
PIK3CA mutation & $1(7 \%)$ & $9(16 \%)$ & 0.695 \\
& & $23(41 \%)$ & 0.025
\end{tabular}

\section{Results}

The mean ages of endometrial and ovarian clear cell carcinoma patients were 71 and 48 years old, respectively. The median follow-up period for patients of ovarian clear cell carcinomas was 31 months (1-207 months). Prognostic factors of endometrial clear cell carcinomas were not evaluated because of the limited number of cases included.

TERT promoter mutations were present in 16\% (9/56) of ovarian clear cell carcinomas and $21 \%$ (3/ 14) of endometrial clear cell carcinomas. In ovarian clear cell carcinomas with TERT promoter mutations, eight cases were $-124 \mathrm{C}>\mathrm{T}$ and one case was $-146 \mathrm{C}>\mathrm{T}$. In endometrial clear cell carcinomas, two cases were $-146 \mathrm{C}>\mathrm{T}$ and one case was $-124 \mathrm{C}>\mathrm{T}$ (Figure 2).

Comparisons of clinicopathological factors of endometrial and ovarian clear cell carcinomas are shown in Table 1. Compared with ovarian clear cell carcinomas, endometrial clear cell carcinomas were characterized by older mean patient age $(P<0.001)$, preserved ARID1A immunoreactivity $(P=0.017)$ and infrequent PIK3CA mutation $(P=0.025)$.

In endometrial clear cell carcinomas, TERT promoter mutations were not correlated with age $(P=0.209)$, loss of ARID1A expression $(P=0.547)$, or PIK3CA mutation $(P=1.000)$. Associations between TERT promoter mutations and other clinicopathological factors in ovarian clear cell carcinomas are listed in Table 2. In ovarian clear cell carcinomas, TERT promoter mutations were correlated to patient age $>45$ years $(P=0.045)$ and preserved ARID1A expression $(P=0.003)$. In early-stage ovarian clear cell carcinomas (FIGO stage I and II), TERT promoter mutations were associated with early relapse within 6 months after chemotherapy $(100 \%$ vs $11 \%, P=0.018$ ), but not correlated to other clinicopathological factors. In advanced-stage ovarian clear cell carcinomas (FIGO stage III and IV), TERT promoter mutations were related to preserved ARID1A expression $(P=0.036)$, but not associated with other clinicopathological factors.

The prognostic effects of clinicopathological factors are summarized in Table 3. The FIGO stage was the only prognostic factor for ovarian clear cell carcinoma $(P<0.001)$. For ovarian clear
Table 2 Correlations between TERT promoter mutation and clinicopathological factors in ovarian clear cell carcinomas

\begin{tabular}{|c|c|c|c|c|}
\hline \multirow[b]{2}{*}{$\begin{array}{l}\text { All patients } \\
(\mathrm{n}=56)\end{array}$} & \multirow[b]{2}{*}{ No. } & \multicolumn{2}{|c|}{ TERT promoter No. (\%) } & \multirow[b]{2}{*}{ P-value } \\
\hline & & $\begin{array}{c}\text { Mutant } \\
\mathrm{n}=9(16)\end{array}$ & $\begin{array}{l}\text { Wild-type } \\
\mathrm{n}=47(84)\end{array}$ & \\
\hline Age & & & & 0.045 \\
\hline$\leq 45$ & 18 & 0 & $18(38)$ & \\
\hline$>45$ & 38 & $9(100)$ & $29(62)$ & \\
\hline FIGO stage & & & & 1.000 \\
\hline $\mathrm{I}+\mathrm{II}$ & 34 & $6(67)$ & $28(60)$ & \\
\hline III + IV & 22 & $3(33)$ & $19(40)$ & \\
\hline Relapse $^{\mathrm{a}}$ & & & & 0.458 \\
\hline Present & 25 & $5(63)$ & $20(45)$ & \\
\hline Absent & 27 & $3(38)$ & $24(55)$ & \\
\hline Relapse period & & & & 0.133 \\
\hline <6 Months & 11 & $4(80)$ & $7(35)$ & \\
\hline$\geq 6$ Months & 14 & $1(20)$ & $13(65)$ & \\
\hline ARID1A expression & & & & 0.003 \\
\hline Negative & 32 & $1(11)$ & $31(66)$ & \\
\hline Positive & 24 & $8(89)$ & $16(34)$ & \\
\hline PIK3CA mutation & & & & 0.074 \\
\hline Mutant & 22 & $1(11)$ & $21(45)$ & \\
\hline Wild type & 34 & $8(89)$ & $26(55)$ & \\
\hline
\end{tabular}

${ }^{\mathrm{a}}$ Not assessed in four cases.

cell carcinoma patients in the early stages, TERT promoter mutations were the only prognostic factor and correlated with shorter diseasefree survival $(P=0.030)$ and overall survival $(P=0.023)$. Kaplan-Meier analysis also revealed that DFS disease-free survival and overall survival were shorter among the TERT promoter mutated patients of the early stages $(P=0.015$ in disease-free survival and 0.009 in overall survival, respectively; Figure 3). In ovarian clear cell carcinoma with advanced staging, FIGO stage IV was the only prognostic factor for ovarian clear cell carcinoma $(P=0.030$ for disease-free survival and 0.002 for overall survival).

\section{Discussion}

This is the first report on the TERT promoter mutations in endometrial clear cell carcinomas. We found that TERT promoter mutations were present in endometrial clear cell carcinomas with similar prevalence and hotspots as in ovarian clear cell carcinomas. In the study by Killela et al, ${ }^{20}$ TERT promoter mutations were present in two of nineteen endometrial carcinomas without specifying histologic type. However, all of the endometrial carcinomas, including 24 endometrioid adenocarcinomas and 12 serous adenocarcinomas, were absent for TERT promoter mutation in the study by Wu et al. ${ }^{21}$ Combined with the findings of ours, Killela, and 
Table 3 Univariate analysis of survival in ovarian clear cell carcinomas of all (a), early-stage (b), and advanced-stage (c) patients

\begin{tabular}{|c|c|c|c|c|c|}
\hline $\begin{array}{l}\text { All patients } \\
(\mathrm{n}=56)\end{array}$ & No. & $\begin{array}{c}\text { Disease-free survival } \\
\text { HR }(95 \% \text { CI) }\end{array}$ & $\mathrm{P}$-value & $\begin{array}{l}\text { Overall survival } \\
\text { HR }(95 \% \text { CI })\end{array}$ & P-value \\
\hline Age & & & 0.129 & & 0.128 \\
\hline$\leq 45$ & 18 & 1.0 & & 1.0 & \\
\hline$>45$ & 38 & $2.34(0.78-7.01)$ & & $2.33(0.78-6.91)$ & \\
\hline FIGO stage & & & $<0.001$ & & $<0.001$ \\
\hline $\mathrm{I}+\mathrm{II}$ & 34 & 1.0 & & 1.0 & \\
\hline III + IV & 22 & $5.84(2.29-14.86)$ & & $5.07(2.04-12.64)$ & \\
\hline TERT promoter & & & 0.123 & & 0.224 \\
\hline Mutant & 9 & 1.0 & & 1.0 & \\
\hline Wild type & 47 & $0.45(0.17-1.24)$ & & $0.54(0.20-1.47)$ & \\
\hline ARID1A expression & & & 0.729 & & 0.665 \\
\hline Negative & 32 & 1.0 & & 1.0 & \\
\hline Positive & 24 & $0.86(0.36-2.03)$ & & $0.83(0.35-1.95)$ & \\
\hline PIK3CA mutation & & & 0.159 & & 0.264 \\
\hline Mutant & 22 & 1.0 & & 1.0 & \\
\hline Wild type & 34 & $1.98(0.77-5.10)$ & & $1.65(0.68-4.00)$ & \\
\hline (b) & & & & & \\
\hline $\begin{array}{l}\text { Early-stage patients } \\
(\mathrm{n}=34)\end{array}$ & No. & $\begin{array}{c}\text { Disease-free survival } \\
\text { HR }(95 \% \text { CI })\end{array}$ & $\mathrm{P}$-value & $\begin{array}{l}\text { Overall survival } \\
\text { HR }(95 \% \mathrm{CI})\end{array}$ & P-value \\
\hline Age & & & 0.226 & & 0.245 \\
\hline$\leq 45$ & 9 & 1.0 & & 1.0 & \\
\hline$>45$ & 25 & $47.53(0.09-246.09)$ & & $39.99(0.08-297.64)$ & \\
\hline FIGO stage & & & 0.058 & & 0.211 \\
\hline I & 29 & 1.0 & & 1.0 & \\
\hline II & 5 & $4.20(0.96-18.46)$ & & $2.61(0.58-11.69)$ & \\
\hline TERT promoter & & & 0.030 & & 0.023 \\
\hline Mutant & 6 & 1.0 & & 1.0 & \\
\hline Wild type & 28 & $0.19(0.04-0.85)$ & & $0.16(0.03-0.78)$ & \\
\hline ARID1A expression & & & 0.950 & & 0.915 \\
\hline Negative & 18 & 1.0 & & 1.0 & \\
\hline Positive & 16 & $0.96(0.24-3.89)$ & & $1.08(0.27-4.32)$ & \\
\hline PIK3CA mutation & & & 0.304 & & 0.294 \\
\hline Mutant & 15 & 1.0 & & 1.0 & \\
\hline Wild type & 19 & $2.37(0.46-12.27)$ & & $2.41(0.47-12.45)$ & \\
\hline (c) & & & & & \\
\hline $\begin{array}{l}\text { Advanced-stage } \\
\text { patients }(\mathrm{n}=22)\end{array}$ & No. & $\begin{array}{c}\text { Disease-free survival } \\
\text { HR }(95 \% \text { CI })\end{array}$ & $\mathrm{P}$-value & $\begin{array}{c}\text { Overall survival } \\
\text { HR (95\% CI) }\end{array}$ & P-value \\
\hline Age & & & 0.335 & & 0.303 \\
\hline$\leq 45$ & 9 & 1.0 & & 1.0 & \\
\hline$>45$ & 13 & $1.77(0.56-5.65)$ & & $1.84(0.58-5.89)$ & \\
\hline FIGO stage & & & 0.030 & & 0.002 \\
\hline III & 18 & 1.0 & & 1.0 & \\
\hline IV & 4 & $3.84(1.14-12.95)$ & & $9.08(2.19-37.65)$ & \\
\hline TERT promoter & & & 0.754 & & 0.832 \\
\hline Mutant & 3 & 1.0 & & 1.0 & \\
\hline Wild type & 19 & $0.79(0.18-3.54)$ & & $0.85(0.19-3.86)$ & \\
\hline ARID1A expression & & & 0.895 & & 0.960 \\
\hline Negative & 14 & 1.0 & & 1.0 & \\
\hline Positive & 8 & $1.08(0.36-3.25)$ & & $0.97(0.32-2.92)$ & \\
\hline PIK3CA mutation & & & 0.582 & & 0.791 \\
\hline Mutant & 7 & 1.0 & & 1.0 & \\
\hline Wild type & 15 & $1.39(0.43-4.44)$ & & $0.85(0.26-2.83)$ & \\
\hline
\end{tabular}

Abbreviations: CI, Confidence interval; HR, hazard ratio. 
a

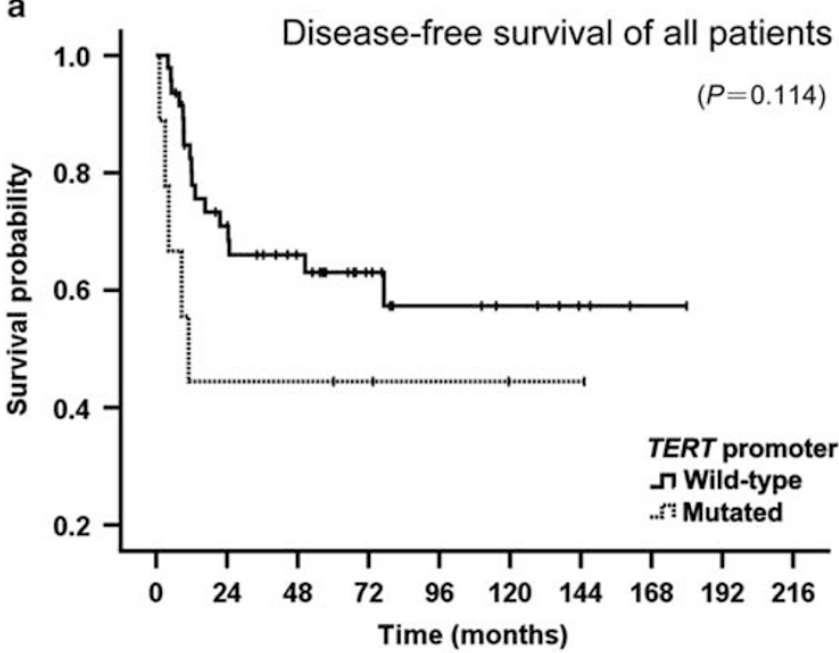

C
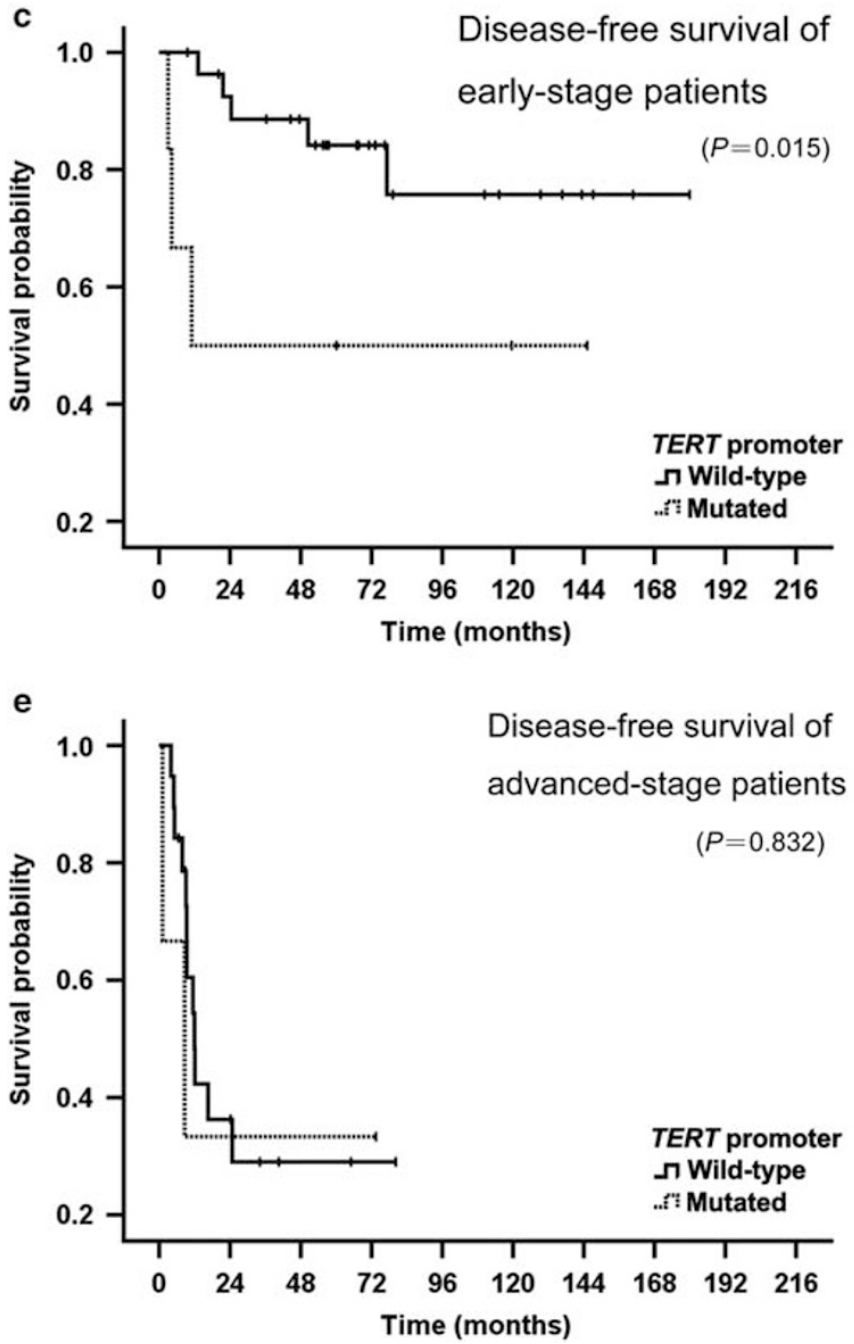

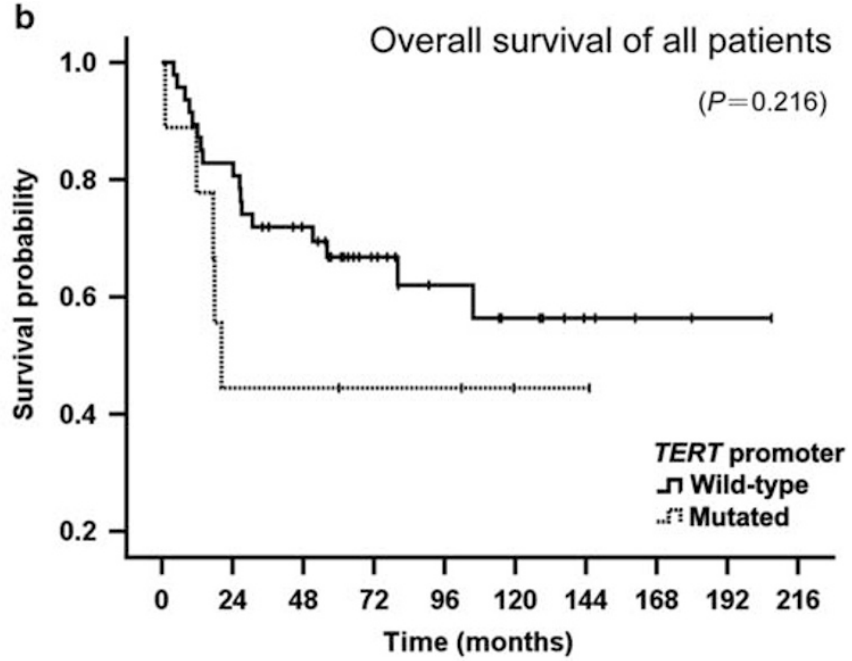

d

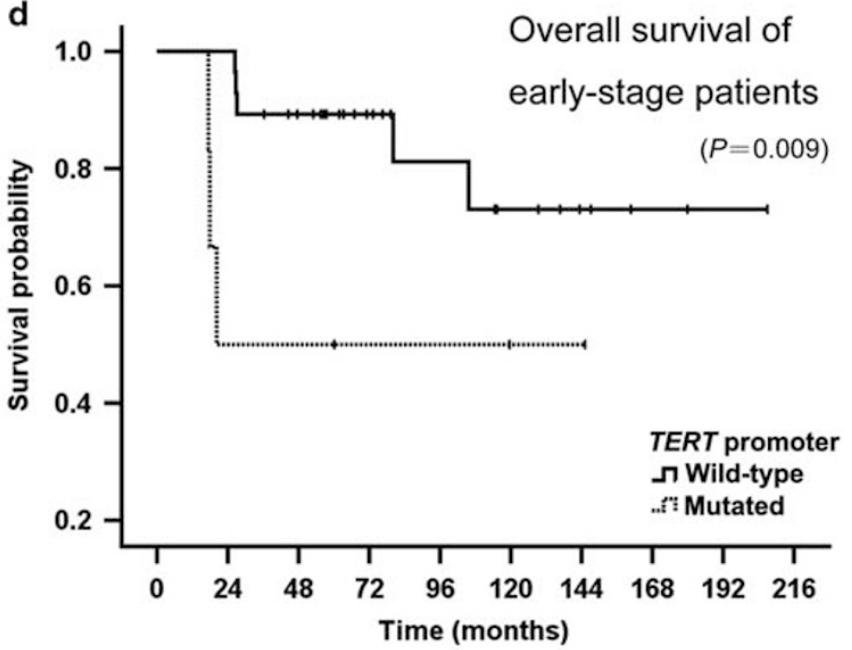

f

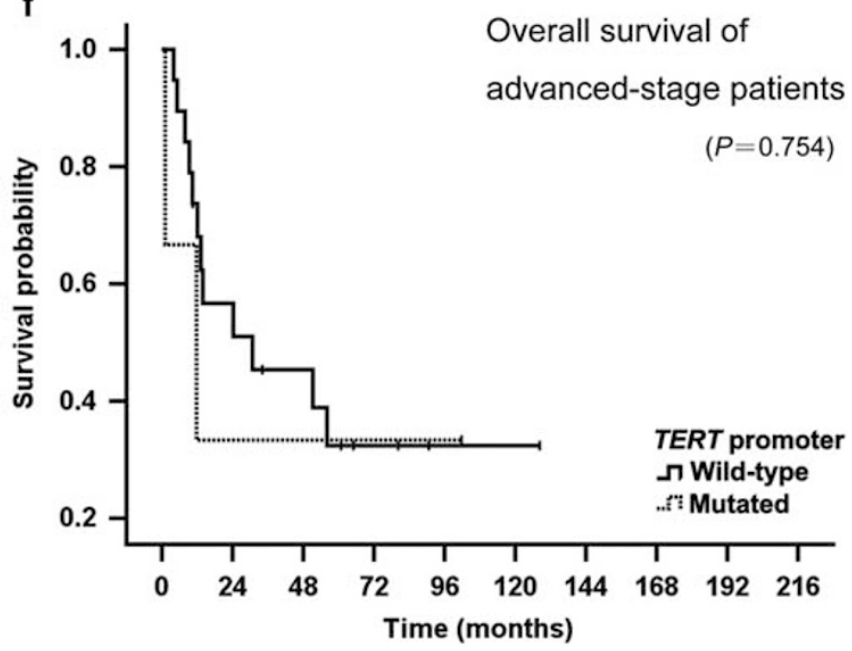

Figure 3 (a) Relationship between disease-free survival and TERT promoter mutation in patients with ovarian clear cell carcinoma. (b) Relationship between overall survival and TERT promoter mutation in patients with ovarian clear cell carcinoma. (c) Relationship between disease-free survival and TERT promoter mutation in patients with early-stage ovarian clear cell carcinoma. (d) Relationship between overall survival and TERT promoter mutation in patients with early-stage ovarian clear cell carcinoma. (e) Relationship between disease-free survival and TERT promoter mutation in patients with advanced-stage ovarian clear cell carcinoma. (f) Relationship between overall survival and TERT promoter mutation in patients with advanced-stage ovarian clear cell carcinoma. 
$\mathrm{Wu}$, we suspect that in carcinomas of endometrial origin, clear cell carcinoma is the predominant histologic type that harbors TERT promoter mutations. Further studies are needed to clarify the relationship between TERT promoter mutations and histologic type of endometrial carcinomas.

Although endometrial and ovarian cell carcinomas shared similar histologic features and a HNF-1 $\beta+$ / ER - immunoprofile, there were statistically significant differences in other clinical data and molecular genetic alterations in this study. We observed that endometrial clear cell carcinomas tended to have patients who were older at presentation, preserved ARID1A expression, and had wild-type PIK3CA gene. These may reflect the different tumor origins and distinct microenvironments during tumor development. Ovarian clear cell carcinoma is often associated with endometriosis. Endometriosis induces a unique microenvironment of long-term blood accumulation with high concentrations of iron and oxidative stress, ${ }^{25}$ which is not encountered in endometrial clear cell carcinoma. Except for ultraviolet radiation, oxidative stress is the other cause of mutagenesis in forms of $\mathrm{C}>\mathrm{T}$ or $\mathrm{CC}>\mathrm{TT}$ substitutions. ${ }^{26}$ This accounts for the possible role of endometriosis-induced oxidative stress in TERT promoter mutations of ovarian clear cell carcinomas. Since endometriosisinduced oxidative stress is not present in the endometrium, characteristics of TERT promoter mutations may be different in endometrial and ovarian clear cell carcinomas. In our study, TERT promoter mutations were present in endometrial and ovarian clear cell carcinomas with similar frequencies. However, we observed that mutations at $-124 \mathrm{C}>\mathrm{T}$ were less frequent in endometrial clear cell carcinomas $(33 \%$ of all TERT promoter mutations) than in ovarian clear cell carcinomas (89\%). In the study by $\mathrm{Wu}$ et $a l^{21}$, 90\% of TERT promoter mutations in ovarian clear cell carcinomas occurred at $-124 \mathrm{C}>\mathrm{T}$. A larger cohort of endometrial clear cell carcinoma is essential to clarify whether $-146 \mathrm{C}>\mathrm{T}$ is the most common type of TERT promoter mutation in this histologic type.

In this study, we observed that TERT promoter mutations were associated with older patient age (>45 years old) in ovarian clear cell carcinomas. The correlation between TERT promoter mutations and older patient age has been shown in glioblastoma, medulloblastoma, ${ }^{20}$ papillary thyroid carcinoma ( $>45$ years old), ${ }^{27}$ and urothelial carcinoma of the urinary bladder ( $>50$ years old). ${ }^{28}$ In contrast, a previous study by $\mathrm{Wu}$ et al showed that no relationship could be found between patient age and TERT promoter mutations. ${ }^{21}$ This discrepancy may be the result of different statistical methodologies and different patient cohorts. In the present study, we used Fisher's exact test and a criterion of 45 years old for patient stratification. As the prevalence of ovarian clear cell carcinoma varies in different races, ${ }^{29}$ different study cohorts may also account for the disparity between the results of $\mathrm{Wu}$ and ours.
In ovarian clear cell carcinomas, we found that TERT promoter mutations were mutually exclusive with loss of ARID1A expression $(P=0.003)$ or PIK3CA mutations $(P=0.074)$. The result is similar to that of Wu et al. ${ }^{21}$ This finding implies independent routes of tumorigenesis between ovarian clear cell carcinomas with mutated TERT promoter and ARID1A or PIK3CA alterations. More studies are necessary to confirm the relationship between TERT promoter mutations and other molecular alterations in endometrial clear cell carcinomas.

In primary glioblastomas, ${ }^{20}$ differentiated thyroid carcinomas $^{30}$ and urothelial carcinomas of the urinary bladder, ${ }^{28}$ TERT promoter mutation was an indicator of poor clinical outcome. In ovarian clear cell carcinomas, Widschwendter et $a l^{15}$ and $\mathrm{Wu}$ et $a^{21}$ reported that TERT expression and TERT promoter mutation revealed no prognostic impact. Our study also demonstrated a similar result in ovarian clear cell carcinomas. In the present study, we further found that in early-stage patients, TERT promoter mutations indicated a likelihood of early relapse within 6 months after chemotherapy and a significantly poorer prognosis. According to the National Comprehensive Cancer Network (NCCN) guidelines, ovarian clear cell carcinomas that recur within 6 months of finishing chemotherapy are viewed as chemotherapy-resistant and should be considered for other therapeutic regimens. ${ }^{31}$ Therefore, our study suggests that early-stage patients of ovarian clear cell carcinoma with TERT promoter mutations deserve a closer follow-up in the first 6 months after chemotherapy. In previous studies, molecular alterations in ovarian clear cell carcinomas, including ARID1A, PIK3CA, and $Z N F 217$, were either not considered a prognostic factor or signified different conclusions. ${ }^{22,24,32-37}$ Our study is the first report on the prognostic impact of TERT promoter mutations in early-stage ovarian clear cell carcinomas. TERT promoter mutations may have a role in the development of chemoresistance, but more in-depth investigations are necessary.

In conclusion, this is the first report demonstrating TERT promoter mutations in endometrial clear cell carcinomas. Although endometrial and ovarian clear cell carcinomas share similar morphological features and some immunoprofiles, there are molecular genetic differences in PIK3CA mutation and ARID1A expression, reflecting their different routes of tumorigenesis and distinct microenvironments. In early-stage ovarian clear cell carcinomas, TERT promoter mutation correlates with early relapse and is a potential molecular genetic change involved with chemoresistance of tumor cells.

\section{Acknowledgments}

This work was supported by 101F008-502 to K-TK and 102-EDN04 to Y-CC. 


\section{Disclosure/conflict of interest}

The authors declare no conflict of interest.

\section{References}

1 Goff BA, Sainz de la Cuesta R, Muntz HG, et al. Clear cell carcinoma of the ovary: a distinct histologic type with poor prognosis and resistance to platinum-based chemotherapy in stage III disease. Gynecol Oncol 1996; 60:412-417.

2 del Carmen MG, Birrer M, Schorge JO. Clear cell carcinoma of the ovary: a review of the literature. Gynecol Oncol 2012;126:481-490.

3 Kuo KT, Mao TL, Jones S, et al. Frequent activating mutations of PIK3CA in ovarian clear cell carcinoma. Am J Pathol 2009;174:1597-1601.

4 Wiegand KC, Shah SP, Al-Agha OM, et al. ARID1A mutations in endometriosis-associated ovarian carcinomas. N Engl J Med 2010;363:1532-1543.

5 Creasman WT, Odicino F, Maisonneuve P, et al. Carcinoma of the corpus uteri. FIGO 26th Annual Report on the Results of Treatment in Gynecological Cancer. Int J Gynaecol Obstet 2006;95(Suppl 1):S105-S143.

6 Huang CY, Chen CA, Chen YL, et al. Nationwide surveillance in uterine cancer: survival analysis and the importance of birth cohort: 30-year populationbased registry in Taiwan. PLoS ONE 2012;7:e51372.

7 Fadare O, Parkash V, Dupont WD, et al. The diagnosis of endometrial carcinomas with clear cells by gynecologic pathologists: an assessment of interobserver variability and associated morphologic features. Am J Surg Pathol 2012;36:1107-1118.

8 Gilks CB, Oliva E, Soslow RA. Poor interobserver reproducibility in the diagnosis of high-grade endometrial carcinoma. Am J Surg Pathol 2013;37:874-881.

9 Hoang LN, Han G, McConechy M, et al. Immunohistochemical characterization of prototypical endometrial clear cell carcinoma-diagnostic utility of HNF-1beta and oestrogen receptor. Histopathology 2014;64: $585-596$.

10 Fadare O, Renshaw IL, Liang SX. Does the loss of ARID1A (BAF-250a) expression in endometrial clear cell carcinomas have any clinicopathologic significance? A pilot assessment. J Cancer 2012;3:129-136.

11 Allo G, Bernardini MQ, Wu RC, et al. ARID1A loss correlates with mismatch repair deficiency and intact p53 expression in high-grade endometrial carcinomas. Mod Pathol 2014;27:255-261.

12 An HJ, Logani S, Isacson C, et al. Molecular characterization of uterine clear cell carcinoma. Mod Pathol 2004;17:530-537.

13 Gunes C, Rudolph KL. The role of telomeres in stem cells and cancer. Cell 2013;152:390-393.

14 Harley CB. Telomerase and cancer therapeutics. Nat Rev Cancer 2008;8:167-179.

15 Widschwendter A, Muller HM, Hubalek MM, et al. Methylation status and expression of human telomerase reverse transcriptase in ovarian and cervical cancer. Gynecol Oncol 2004;93:407-416.

16 Horn S, Figl A, Rachakonda PS, et al. TERT promoter mutations in familial and sporadic melanoma. Science 2013;339:959-961.

17 Huang FW, Hodis E, Xu MJ, et al. Highly recurrent TERT promoter mutations in human melanoma. Science 2013;339:957-959.
18 Vinagre J, Almeida A, Populo H, et al. Frequency of TERT promoter mutations in human cancers. Nat Commun 2013;4:2185.

19 Landa I, Ganly I, Chan TA, et al. Frequent somatic TERT promoter mutations in thyroid cancer: higher prevalence in advanced forms of the disease. J Clin Endocrinol Metab 2013;98:E1562-E1566.

20 Killela PJ, Reitman ZJ, Jiao Y, et al. TERT promoter mutations occur frequently in gliomas and a subset of tumors derived from cells with low rates of self-renewal. Proc Natl Acad Sci USA 2013;110: 6021-6026.

$21 \mathrm{Wu}$ RC, Ayhan A, Maeda D, et al. Frequent somatic mutations of the telomerase reverse transcriptase promoter in ovarian clear cell carcinoma but not in other major types of gynaecological malignancy. J Pathol 2014;232:473-481.

22 Huang HN, Lin MC, Huang WC, et al. Loss of ARID1A expression and its relationship with PI3K-Akt pathway alterations and ZNF217 amplification in ovarian clear cell carcinoma. Mod Pathol 2014;27:983-990.

23 Lee KR, Tavassoli FA, Part J, et al. Surface epithelialstromal tumours, In: Tavassoli FA, Devilee P (eds). World Health Organization Classification of Tumours. Pathology and Genetics of Tumours of the Breast and Female Genital Organs. IARC Press: Lyon; 2003, pp 117-145.

24 Maeda D, Mao TL, Fukayama M, et al. Clinicopathological significance of loss of ARID1A immunoreactivity in ovarian clear cell carcinoma. Int J Mol Sci 2010; 11:5120-5128.

25 Yamaguchi K, Mandai M, Toyokuni S, et al. Contents of endometriotic cysts, especially the high concentration of free iron, are a possible cause of carcinogenesis in the cysts through the iron-induced persistent oxidative stress. Clin Cancer Res 2008;14:32-40.

26 Shin-Darlak CY, Skinner AM, Turker MS. A role for Pms2 in the prevention of tandem CC $->$ TT substitutions induced by ultraviolet radiation and oxidative stress. DNA Repair (Amst) 2005;4:51-57.

27 Liu T, Wang N, Cao J, et al. The age- and shorter telomere-dependent TERT promoter mutation in follicular thyroid cell-derived carcinomas. Oncogene 2013 (e-pub ahead of print).

$28 \mathrm{Wu} \mathrm{S}$, Huang $\mathrm{P}$, Li $\mathrm{C}$, et al. Telomerase reverse transcriptase gene promoter mutations help discern the origin of urogenital tumors: a genomic and molecular study. Eur Urol 2014;65:274-277.

29 Chan JK, Teoh D, Hu JM, et al. Do clear cell ovarian carcinomas have poorer prognosis compared to other epithelial cell types? A study of 1411 clear cell ovarian cancers. Gynecol Oncol 2008;109:370-376.

30 Melo M, da Rocha AG, Vinagre J, et al. TERT promoter mutations are a major indicator of poor outcome in differentiated thyroid carcinomas. J Clin Endocrinol Metab 2014;99:E754-E765.

31 Morgan RJ Jr, Alvarez RD, Armstrong DK, et al. Ovarian cancer, version 2.2013. J Natl Compr Canc Netw 2013;11:1199-1209.

32 Katagiri A, Nakayama K, Rahman MT, et al. Loss of ARID1A expression is related to shorter progressionfree survival and chemoresistance in ovarian clear cell carcinoma. Mod Pathol 2012;25:282-288.

33 Yamamoto S, Tsuda $\mathrm{H}$, Takano $\mathrm{M}$, et al. PIK3CA mutations and loss of ARID1A protein expression are early events in the development of cystic ovarian clear cell adenocarcinoma. Virchows Arch 2012;460: 77-87. 
34 Rahman MT, Nakayama K, Rahman M, et al. Prognostic and therapeutic impact of the chromosome 20q13.2 ZNF217 locus amplification in ovarian clear cell carcinoma. Cancer 2012;118:2846-2857.

35 Ho CM, Lin MC, Huang SH, et al. PTEN promoter methylation and LOH of 10q22-23 locus in PTEN expression of ovarian clear cell adenocarcinomas. Gynecol Oncol 2009;112:307-313.
36 Rahman M, Nakayama K, Rahman MT, et al. Clinicopathologic and biological analysis of PIK3CA mutation in ovarian clear cell carcinoma. Hum Pathol 2012; 43:2197-2206.

37 Abe A, Minaguchi T, Ochi $\mathrm{H}$, et al. PIK3CA overexpression is a possible prognostic factor for favorable survival in ovarian clear cell carcinoma. Hum Pathol 2013;44:199-207. 